I FELICIDADE O MEDINDO A FELICIDADE DO BRASILEIRO 


\section{MEDINDO A FELICIDADE DO BRASILEIRO}

\section{De que forma a felicidade, ou, em certos casos, a falta dela, afeta o dia-a-dia do brasileiro? Em quais aspectos da vida somos mais felizes? Um projeto em desenvolvimento na FGV-EAESP tem por objetivo apresentar respostas}

| POR FABIO GALLO GARCIA + WESLEY MENDES-DA-SILVA

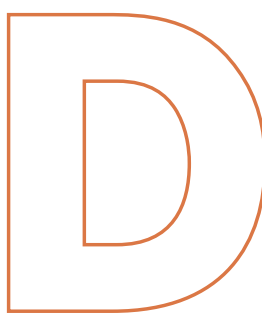

iscutir felicidade é, certamente, algo ousado. Há quem considere que felicidade é como gosto: não se discute, por ser essencialmente pessoal. É difícil até mesmo definir seu conceito: cada um tem a sua própria ideia de felicidade.

Apesar disso, muitos pesquisadores se esforçam em estudá-la. Disciplinas como filosofia, psicologia, medicina, teologia, sociologia e antropologia, cada qual com seu viés, oferecem diferentes interpretações. Em meio a essa multiplicidade de visões, uma alternativa é estudar a questão de maneira mais ampla, buscando entender como a felicidade afeta o dia-a-dia das pessoas.

\section{FELICIDADE E SATISFAÇÃO COM A VIDA}

Um avanço recente nos estudos sobre o progresso ou desenvolvimento dos países consistiu em levar em consideração o grau de satisfação das pessoas com suas próprias condições de vida. Esse tema tem sido tratado com frequência, em análises econômicas, como um sinônimo de felicidade. Vários autores têm dedicado esforços para a criação de um repertório conceitual que permita avançar a pesquisa em torno de um

\section{EMBORA O BRASIL APRESENTE O SÉTIMO PIB DO MUNDO, ESTAMOS NA $85^{\circ}$ POSIÇÃO NO IDH}

assunto tão provocativo. O debate vai além das discussões sobre o conceito de felicidade - ou de bem-estar, ou de satisfação com a vida, como queiramos - e se volta ao desafio de medi-lo.

Nesse contexto, alguns pressupostos que poderiam parecer óbvios revelam-se controversos. Em um estudo recente, denominado The happiness-suicide paradox (O paradoxo felicidade-suicídio), pesquisadores norte-americanos e britânicos se propuseram a entender as razões pelas quais, ao contrário do que se esperaria, elevados índices de mortes por suicídio são verificados em países economicamente desenvolvidos, onde as pesquisas detectam altos índices de felicidade ou satisfação com a vida. Áustria e Suíça, por exemplo, são lugares onde esse paradoxo se verifica. A conclusão dos autores é que, aparentemente, as pessoas 
podem achar particularmente doloroso ser infeliz em um lugar feliz, de modo que a decisão de cometer suicídio é influenciada por comparações relativas.

De maneira aparentemente análoga, dados relativos ao contexto brasileiro atestam que as maiores taxas de morte por suicídio têm sido verificadas nas regiões do país que exibem os mais elevados indicadores de desenvolvimento. Segundo dados do Ministério da Saúde, entre as 50 cidades com maior taxa de suicídio, dez estão localizadas no Rio Grande do Sul.

\section{FELICIDADE À BRASILEIRA}

Quando se pensa no Brasil, outra questão vem imediatamente à cabeça: não somos um povo reconhecidamente feliz? Sendo assim, será realmente necessário medir a nossa felicidade?

É certo que a sociedade brasileira, nas últimas décadas, vem dando mostras de inegável melhora em seus indicadores sociais, principalmente com relação a educação, saúde e condições gerais dos domicílios. No entanto, a distância entre os extremos ainda é muito grande. Há desigualdades de todos os tipos e o fato é que, embora sejamos a sétima nação do mundo em termos de Produto Interno Bruto (PIB), estamos na $85^{\mathrm{a}}$ posição no Índice de Desenvolvimento Humano (IDH). Daí decorre uma pergunta: somos realmente felizes? Apesar de, no nível internacional, sermos conhecidos por deter níveis elevados de felicidade, aqui não temos uma resposta clara, mas não resta dúvida de que devemos buscá-la.

\section{FELICIDADE EM NÚMEROS}

Com esse objetivo, em 2012 foi iniciada no âmbito do Instituto de Finanças da FGV-EAESP uma agenda de pesquisa voltada principalmente ao desenvolvimento de uma metodologia para mensurar o nível de felicidade dos residentes no Brasil. O objetivo é criar um índice de bem-estar, o Well Being Brasil (WBB), cujo foco não estará na comparação com outros países, mas sim na mensuração do nível de bem-estar subjetivo dos brasileiros, a partir de seus próprios anseios e demandas.

O primeiro relatório do WBB foi divulgado em janeiro de 2014, com resultados obtidos, nesse primeiro momento, na cidade de São Paulo. A pesquisa foi realizada entre os dias 10 e 30 de novembro de 2013 e ouviu 786 pessoas. A amostra foi planejada de modo a refletir a composição da população paulistana em termos de idade, sexo e demais características sociodemográficas.

Aplicaram-se 68 questões, que buscaram avaliar a satisfação da população em relação a dez grupos de

\section{AS MAIORES TAXAS DE MORTE POR SUICÍDIO TÊM SIDO VERIFICADAS EM REGIÕES QUE EXIBEM OS MAIS ELEVADOS INDICADORES DE DESENVOLVIMENTO}

variáveis, a saber: saúde, educação, segurança, poder público, meio ambiente, transporte e mobilidade, família, profissão e dinheiro, consumo, e redes de relacionamento. O relatório, com uma descrição detalhada da pesquisa, está disponível na internet, mas vale a pena apresentar aqui uma síntese dos resultados.

\section{ONTEM, HOJE E AMANHÃ}

O primeiro resultado a ser destacado é o nível de satisfação geral com a vida revelado pelos respondentes. Em uma escala de 5 pontos, em que 1 significa "pouco satisfeito" e 5, "muito satisfeito", o grau de satisfação dos respondentes em relação à sua vida atual é, em média, 3,69. Ademais, a evolução dessa satisfação no tempo, mostrada no gráfico abaixo, sugere que os participantes de maneira geral se sentem mais felizes hoje do que estavam no passado recente, além de estarem otimistas em relação à sua vida no futuro.
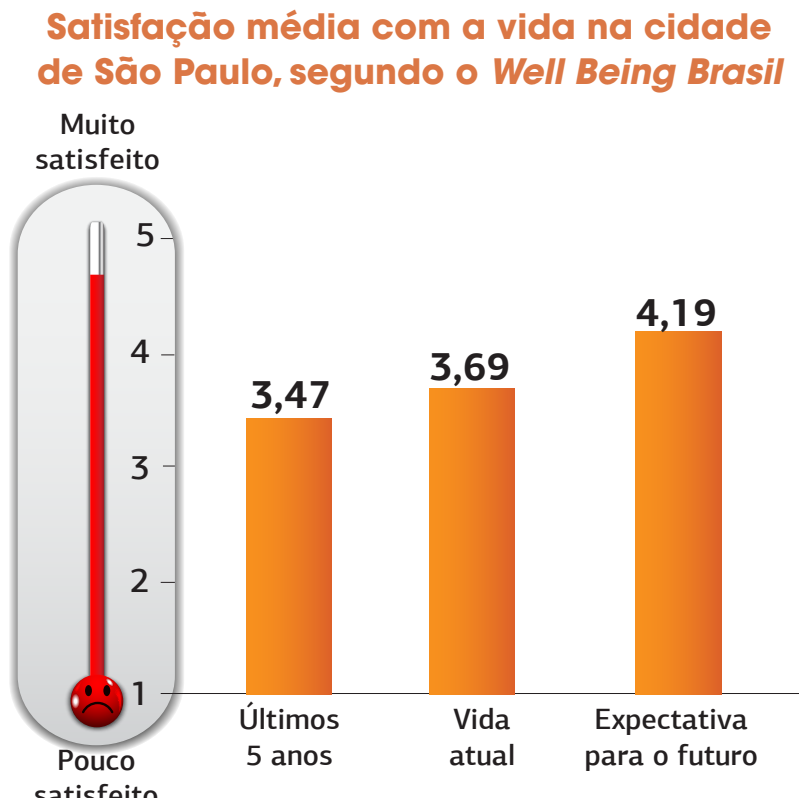

FONTE: RELATÓRIO WELL BEING BRASIL CIDADE DE SÃO PAULO 


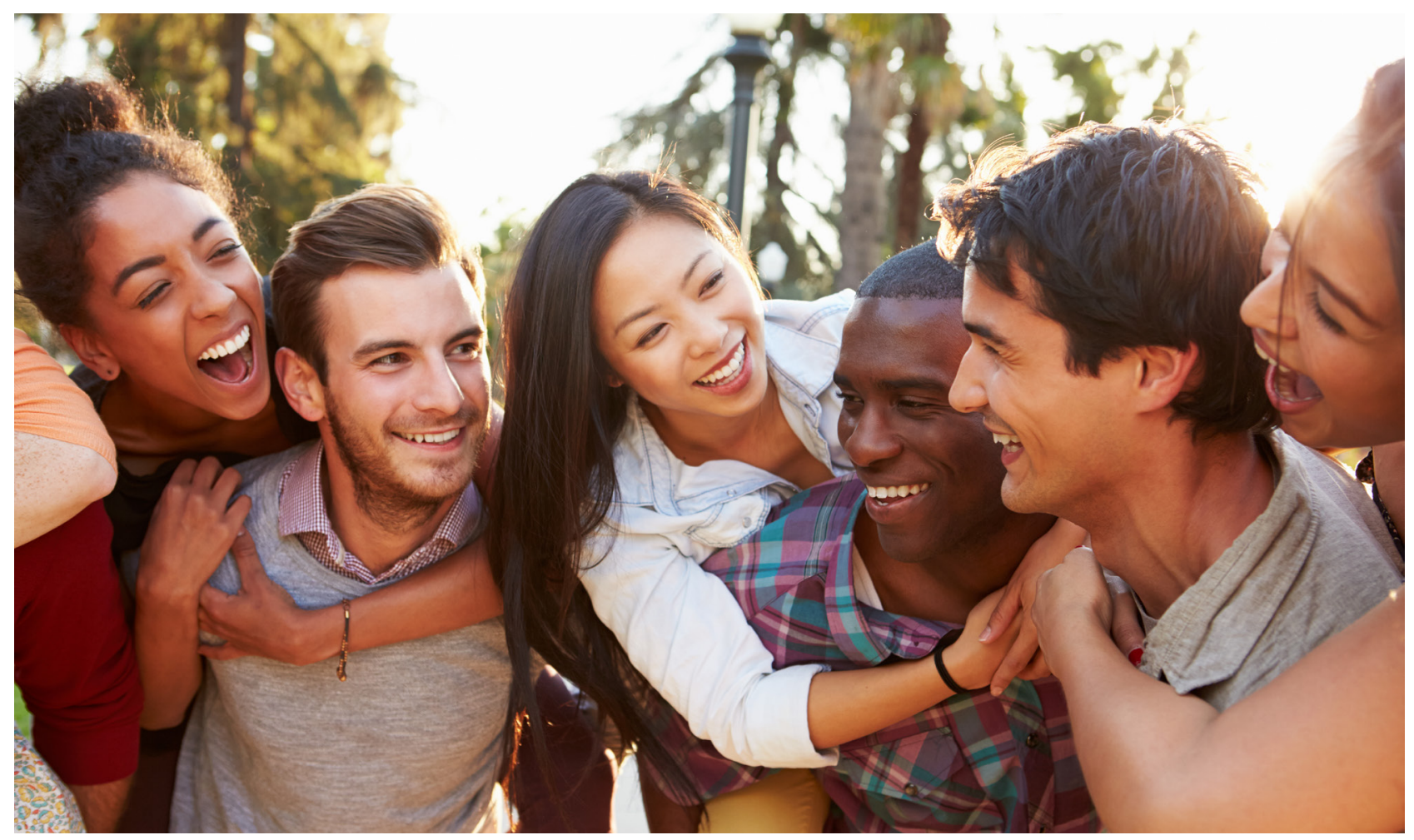

\section{O QUE NOS TORNA FELIZES}

Outro resultado que vale a pena destacar está na tabela ao lado, que sintetiza os ratings médios obtidos para cada uma das dimensões do índice. A primeira coluna de dados representa o grau de importância (em uma escala de 1 a 5) atribuído pelos respondentes a essas dimensões (grupos de variáveis). A segunda coluna indica o grau de satisfação dos participantes com sua vida atual, no que se refere às mesmas dimensões.

Nota-se que, embora os respondentes tenham considerado as dez dimensões igualmente relevantes para o seu bem-estar (todas com ratings de relevância oscilando entre 4,5 e 4,8), o desempenho delas em termos de satisfação foi relativamente desigual: o paulistano se revela bastante satisfeito em relação a "família" e "redes de relacionamento", por exemplo, mas está pouco feliz nos quesitos "poder público", "transporte e mobilidade" e "segurança".

Em breve a pesquisa será ampliada para outras regiões do Brasil. Seus resultados, dos quais pudemos comentar aqui apenas uma pequena parte, parecem constituir matéria de interesse da comunidade acadêmica, do governo e do meio corporativo. Resta-nos o esforço na direção de constituir as bases necessárias ao desenvolvimento dessa importante agenda de pesquisa.

\begin{tabular}{|lcc|}
\hline \multicolumn{1}{c}{$\begin{array}{c}\text { Ratings médios obtidos pora } \\
\text { as dimensōes do Well Being Brasil }\end{array}$} \\
\hline \multirow{2}{*}{ Dimensões } & \multicolumn{2}{c|}{ Ratings médios } \\
\cline { 2 - 3 } & Relevância & Satisfação \\
\hline Família & 4,688 & 3,842 \\
Redes de relacionamento & 4,515 & 3,612 \\
Saúde & 4,721 & 3,323 \\
Consumo & 4,521 & 3,299 \\
Vida profissional e financeira & 4,775 & 3,298 \\
Educação & 4,552 & 3,068 \\
Segurança & 4,624 & 2,694 \\
Transporte e mobilidade & 4,609 & 2,574 \\
Meio ambiente & 4,563 & 2,281 \\
Poder público & 4,561 & 1,831 \\
\hline
\end{tabular}

Ratings expressos em uma escala de 1 (pouco relevante/pouco satisfeito) a 5 (muito relevante/muito safisfeito).

- Well Being Brasil cidade de São Paulo (relatório de pesquisa). Núcleo de Estudos sobre a Felicidade e o Comportamento Financeiro da FGV-EAESP. Disponível em: www.wbbindex.org. The happiness-suicide paradox. Mary C. Daly, Andrew J. Oswald, Daniel Wilson e Stephen Wu. Disponivel em: www.frbsf.org/economic-research/files/wp10-30bk.pdf.
}

FABIO GALLO GARCIA > Professor da FGV-EAESP > fabio.gallo@fgv.br WESLEY MENDES-DA-SILVA > Professor da FGV-EAESP > wesley.mendes@fgv.br 